\title{
A Lexical Approach to College English Teaching
}

\author{
Ke Liu \\ Huanghe Science and Technology College \\ Zhengzhou, China 450006
}

\begin{abstract}
Vocabulary is always considered as an important standard to evaluate learners' language competence. How to improve vocabulary teaching is becoming more concerned in language teaching. Due to the development of lexical chunks theory, a lexical approach to language teaching has gradually replaced the traditional teaching method centered on grammar. The paper surveys the importance of chunks in language learning and the application of chunks theory in English teaching.
\end{abstract}

\section{Keywords—lexical chunk; lexical approach; English teaching}

\section{INTRODUCTION}

In recent years, with the development of corpus linguistics and second language acquisition, chunk theory has become a trend of language research and language teaching research. A lexical approach has become the hot topic in the study of foreign language teaching. Lexical chunks are the main components of a language, and also the main content in language learning. More and more researchers believe that the key to successful language learning is to master a lot of lexical chunks, which is a reflection of learners' language competent, so teaching chunks should be the primary task of language teaching. Professor Ding Yan believed that chunk knowledge is a better predictor of one's language proficiency compared with grammar knowledge. Lexical chunks occupy an important role in language system, and grammar knowledge is located in the second.

\section{AN OVERVIEW OF CHUNK THEORY}

Psychological linguistics found that in people's memory there are a large nu mber of prefabricated language units which are called prefabricated chunks. Different linguists have made different definitions, such as Lyuons (1968) who argues that a prefabricated chunk is "a phrase used in special occasions as an integral whole", Ellis (1994) who regards it as a sequence of greeting words like greetings, it is fixed and predictable, and thus to facilitate learners' memory. In a nutshell, chunks are the multiword units with higher frequency over a single word in verbal communication (Duan Shiping, 2008). Lexical chunks are featured by predictability, stationarity and easy access. Prefabricated chunks are not temporarily generated according to grammar rules in language use, but are already stored in the memory (Chen wan, 2008); stationarity (or integrity) means that chunks as a whole cannot be analyzed in a sentence, which makes chunks can be extracted quickly from memory.
Chunk researches show that the lexical chunk in an effective way in the improvement of interlanguage, it guides the learners to pay attention to context, prag matics, discourse content and its generative, helping learners to use chunks properly and creatively so as to improve the fluency of language and make smooth communication. Therefore, a lexical approach has gradually formed since 1980s, which is the opposite of the traditional grammar centered teaching method.

Widdowson (1989) pointed out the advantages of lexical approach to language teaching. He concluded two extremes in the present language teaching methods, the one is structure teaching method which pays too much attention to grammar rules, ignoring the application of the language, and the other on is communicative teaching method which understate the importance of grammar. Chunks teaching method avoids these two mistakes by combining grammar teaching and language use.

Willis (1990) thinks that the teaching approach based on "chunks" could promote the ability of using language more effectively. Nattinger and Decarric (1992) have discussed that the lexical approach could be better to help learners to understand and produce accurate discourse structure and framework of different style. Michael Lewis (1993) put forward "lexical chunks", which laid the foundation of lexical approach. He also made a conclusion of L1 learning studies which are beneficial to L2 learning, language is acquired not by learning a single sound, structure or its combination, but by improving the ability of analyzing the whole structure. Grammar acquisition is a process of observation, hypothesis and experiment. We can effectively use the phrases without having to understand their parts. Acquisition can be promoted by talking to people with higher language proficiency.

\section{THE CLASSIFICATION AND FUNCTION OF LEXICAL CHUNKS}

\section{A. The Classification of Lexical Chunks}

Different scholars have different descriptions about the classification of chunks, the most influential and practical one is given by Lewis who divides chunks into four categories: 1) words and polywords, such as to some extent, firefighter, whereas, etc. 2) collocations with high frequency such as green hands, pay attention to, a large sum of, etc. 3) institutionalized utterances, which refer to fixed or semi-fixed collocation or sentence pattern, such as It is important that..., I'd rather..., good luck to you, ect. 4) sentence frames and heads, which 
refer to incomplete sentences with specific prag matic functions, such as on one hand, on the other hand, put a sock in it, etc. these are usually used in oral expression as important devices for discourse coherence.

Thus it can be seen that Lewis definition of chunks has already broken through the traditional concept of words, chunks are not just the combination of words, and they have reached the range of phrases, idioms and even sentences.

\section{B. The Function of Lexical Chunks in Second Language Learning}

1) To improve the efficiency of vocabulary acquisition: Chunks are prefabricated language units with a pragmatic function, which are stored in long-term memory, containing most used formula language and patterns. Therefore chunks are high frequency words. People need to extract words from their memory in language output, which is a process of activating vocabulary knowledge. The main factors that have impact on this process include word frequency, semantic meaning and context. High frequency words which are often used tend to be extracted more easily and quickly. Therefore, learning lexical chunks is helpful to relieve learners' memory burden, and help the listener to speed up understanding and to understand the speaker's intention correctly by simplifying and accelerating the decoding process the brain. Nattinger and DeCarrico's research shows that the more chunks are stored in the brain, the more capable to organize language. So learners need to know that lexical chunks should be given much priority over single words or grammar in language learning. Acquiring lexical chunks helps learners to improve their comprehensive ability in listening and reading, and also to promote their ability in language output.

2) To improve the accuracy of language expression: Learning chunks is helpful to overcome the negative transfer of mother tongue. The output of the language is not only the language activity, but also a thinking activity. Although many learners have acquired some grammar rules and a large number of words, and can generate grammatically correct sentences according to the rules, but due to the influence of the thinking mode of mother tongue, their expressions are still different from the expressions of native speakers.

Lexical chunks are stored and extracted in fixed patterns, so learners don't need to generate sentences on the spot according to grammatical rules, what they need to do is to combine lexical chunks into a sentence, or to replace some words in the chunks. In this way, learners could learn the native language expressions and the thinking mode of the target language, so as to reduce the negative transfer of native language in actual communication, which helps to bridge the gap between L2 learners and native speakers in terms of words choosing and discourse output.

3) To improve the fluency of language communication: Pawley and Syder (1983) pointed out that second language learners have two big problems, namely the fluency and word choice in communication. Chunks are stored in the memory in certain forms, although the form has certain variability, but the change is limited, so they can be integrated to direct use, usually don't have to be generated temporarily in verbal communication according to the rules of grammar. Therefore, lexical chunks in language use have greater advantages over single word, because it is quite faster to search for or extract chunks, and to use them in communication, which is very important to improve learners' fluency in oral and written language. Therefore, using a large number of word blocks is an important means to improve language competence, for learners can use authentic language to express ideas, which are more acceptable and understandable, so as to get close to native speakers.

\section{THE APPLICATION OF CHUNK THEORY TO ENGLISH TEACHING}

Lexical chunks play an important role in language learning, so teachers should consciously help students establish their sense of lexical chunks, to identify chunks in language learning by proving them a large number of chunks material, to improve their sensitivity towards lexical chunks, gradually, therefore, train students to accumulate chunks and enhance their ability to use them. Chunks learning is an important part of language learning, which is also an effective way to improve students' comprehensive ability. In English teaching practice, teachers can help students learn chunks from the following three aspects.

\section{A. To Help Students Establish Chunk Consciousness}

Traditional teaching approach lays its emphas is on words and grammar, and making sentence with words according to grammar rules. With the development of chunk theory, the teaching emphasis has shifted from words to chunks, thus teachers should help students establish their consciousness to chunks. First of all, students need to know the significance of learning chunks in language learning, and secondly, students should learn the classification of chunks so as to identify chunks in learning material. At last, students should be required to use chunks in oral and written communication so that they can enhance their language competence.

In order to help students establish chunk consciousness, teachers can design a flow of activities of enhancing students' consciousness of lexical chunks from the very beginning. Students may have a general understanding of chunks in the application of chunks in communication, and thus their sensitivity of chunks will be raised. Second, teachers should help students shift their focus from learning words to learning chunks, and make them realize the importance of lexical chunks clearly and participate in the design of chunk learning goals and requirements in one semester. The activity can take the form of competition, students are required to brainstorm collocation with words "get, run, give, take, bring", which can guide students to understand the meaning of the word meaning and type, help teachers to understand students' vocabulary level, and help to increase students' interest in learning lexical chunks. Or teachers may provide students with some sentences or a short essay, and require students to find out all the chunks and then translate them, this activity can help students to 
identify and analyze chunks. Before text analyzing, students can ask students to preview the text and mark the chunks in it, this process requires students possess relevant background knowledge, clear conte xtual clues, especially certain language knowledge, thus it is beneficial to help students establish their consciousness of chunks. In formal classroom teaching, teachers should help students to verify the information in the preview, to examine students' work in identifying chunks. Moreover, teachers should not only focus on the chunks in the word list, but also provide students with new and important chunks from other resources in preparing lessons. Lexical chunks with special structure or difficult meaning should be taken as teaching focus in English teaching.

\section{B. To Teach Chunks in Context}

Context is an important concept in pragmatics, for a certain context has decided the meaning of utterance; every single sentence takes place in a specific context. Psychological linguistics believe that everyone has their own library of prefabricated chunks, the native Speakers, despite the fact that most of the prefabricated language chunks are similar, vary in the chunks they use due to different age, gender, class, culture and personal experience. One's lexical chunks will expand with the passage of time and gaining experience, which sheds some light on English teaching that chunks should be learned in context, which students are familiar with or related to their personal experience. In this way, language students are easy to make as sociation and to understand the meaning of chunks in a certain context. Moreover, it is more effective to memorize lexical chunks in context than to learn chunks alone. For example, taking library as the language context, teachers can provide students with such a sentence.

Once the information in your card is confirmed by the computer You get immediate access to the library. On the first floor of the library there are computers hooked up to the Internet, You can surf on the internet and look for the book you want.

The underlined parts are chunks, another example is the dining hall which is familiar to students.

On the fourth floor of the third canteen there are all kinds of shops. Thanks In shops, you can try on the and buy the coats jeans shoes and the like. In electronic products shops you can buy portable storage devices electronic dictionaries and so On. Maybe you have an opportunity to open up your own shop in the future.

Moreover, teachers can make use of many kinds of teaching activities to raise the frequency of using chunks, for example, teachers can assign a task of pair work, which requires students to make up a dialogue centered on a given topic related to the learning text. In this activity, students are encouraged to use chunks they have learned, which can improve their pragmatic ability of using chunks. Besides, teachers can ask students to make a courseware and give a topic report in the first few minutes of each class period, the oral presentation can help students the consolidate their chunk knowledge. Except for oral practice, teacher can also enhance chunks practice by the means of writing after each unit; in this way can students have a review of the language points, and also improve their writing competence by using chunks creatively and properly. Writing and speaking are two important parts of language output, which can be used effectively in chucks practice. Only through practice can learners improve their efficiency and accuracy to extract and use chunks according to the situation. Teachers must follow the rules of linguistics to create pragmatic situation that corresponds with actual discourse so as to promote students' ability to use chunks effectively in a specific situation.

\section{To Strengthen the Drill of Chunks}

The purpose of learning a language is to apply it into use; therefore, teachers should strengthen application of chunks in daily teaching. Using chunks can be divided into two levels: the low level of using chunks mainly includes English-Chinese translation, words replacement, making sentences, chunks expanding, etc. the high level of lexical chunks using method mainly includes oral presentations, oral communication, storytelling, written and oral report, etc.

According to modern teaching theory, a large quantity of contact, experience and application is a prerequisite for learning foreign language. Therefore, teachers should immerse the chunk theory into the teaching process of each lesson, and strengthen the practice and application of chunks. For example, in the review, teachers can guide the student to apply as many chunks that learned as possible to retell the text content; or teachers can design a variety of exercises to help students practice and use the chunk, such as choosing words, blank filling, complete the sentences, writing with given chunks. In order to accelerate internalized absorption of chunks, teachers can also design task-oriented teaching activity such as oral composition to stimulate students' learning interest and enthusiasm, increase the output of the language and creative use of lexical chunks.

\section{To Cultivate Students' Self-Learning Ability}

The key to language learning is not to teaching but learning, English is a practical course, so students' self-learning ability is directly related to the success of their study. The amount of time to learn English in class is limited, so a lot of time is needed after class to practice language. Besides, the number of chunks learned in class is far from enough, so learners need to learn more chunks after class by themselves. Therefore, in a lexical approach to English teaching, emphas is should be put on cultivating students' self-learning ability and their chunks acquisition habit.

Self-learning ability refers to learners' ability to plan, manage, supervise and assess the learning process. This ability is not born with; it's acquired through education or other ways. So teachers should penetrate the concept of chunks into teaching, paying attention to cultivate students' learning enthusiasm and motivation, and promote students' willingness to learn.

- Teachers should emphasize the importance and necessity of independent learning and accumulating chunks in language learning, and to change students' habit of relying on teachers in learning. Teachers should mobilize students' self-learning consciousness 
and cultivate their self-learning ability based on classroom teaching. First of all, teachers need to train students to form the habit of memorizing and using word in chunks, and get rid of the traditional way of learning words. Words are presented to students in chunks according to their meaning and contexts are given to strengthen the acquisition of chunks.

- Teachers should give students some guidance and training about learning strategies and methods, such as knowledge about roots and affixes, the rule of word form and the evolving process of word meaning, etc. which should be involved in the teaching process while analyzing the words, so as to enlarge students' vocabulary size and improve their chunk recognition and word guessing ability and enhance students' language competence through effective learning strategies.

- Teachers should try their best to provide or create proper environment to learn chunks, effectively make use of all available teaching resources, including all kinds of listening and reading material, news paper and magazines in web-based autonomous learning center. At the same time, to create a good learning atmosphere through all types of campus activities such as English school radio, English speech singing contest. Students should be encouraged to use all kinds of chunks flexibly and creatively so as to improve the efficiency of learning words.

\section{CONCLUSION}

Chunks are of great importance to second language learners in the improvement of language ability, which have direct relation to students' language competence. Therefore, teachers should fully aware of the role of lexical chunks in English learning. In the teaching, teachers should consciously cultivate students' sensitivity to chunks and encourage students to accumulate chunks through reading or English movies or songs, so that students' vocabulary will be enlarged and their language ability will be promoted.

\section{REFERENCES}

[1] Ellis R. The Study of Second Language Acquisition [M]. Shanghai: Shanghai Foreign Language Teaching Publications, 1999.

[2] Lewis M. The Lexical Approach [M]. Hove, England Language Teaching Publications, 1993.

[3] Nattinger J.\& Decarfico J. Lexical Phrases and Language Teaching[M]. Shanghai: Shanghai Foreign Language T eaching Publications, 2000.

[4] Wray A. Formulaic Language and the Lexicon [M]. Cambridge : Cambridge University Press, 2002. 